\title{
Aspectos Poéticos e Retóricos na Composição do Enredo da Narrativa Histórica da Etnomatemática
}

\author{
Poetic and Rhetoric aspects in the composition of the Storytelling of the Historical \\ Narrative of Ethnomathematics
}

\author{
Fabio Lennon Marchon ${ }^{1}$ \\ Maria Cecilia Fantinato ${ }^{2}$
}

\begin{abstract}
Resumo
Este artigo apresenta um recorte da tese de doutorado defendida pelo primeiro autor deste trabalho, orientado pelo segundo autor, e trata dos aspectos literários/poéticos e retóricos do texto assinado por Ubiratan D'Ambrosio. Investigam-se os modos como D'Ambrosio conta histórias da História, especialmente no contexto da sua produção escrita em Etnomatemática. Busca-se evidenciar algumas das estratégias discursivas empregadas pelo escritor/autor ao compor os enredos (intrigas) das suas historias. A metodologia da pesquisa buscou na Hermenêutica narratológica ricoeuriana suas bases analíticas e interpretativas, sendo a composição do enredo/intriga o fio condutor da tarefa empreendida. As narrativas históricas elaboradas por D'Ambrosio, no plano do texto, efetuam um entrecruzamento referencial entre a representação factual dos fatos e a ficcionalização da História.
\end{abstract}

Palavras-chave: Poética, retórica, mundo do texto, histórias da História.

\section{Abstract}

This article presents a cut of the doctoral thesis defended by the first author of this work, guided by the second author, and deals with the literary / poetic and rhetorical aspects of the text signed by Ubiratan D'Ambrosio. We investigate the ways D'Ambrosio tells stories of history, especially in the context of his written production in Ethnomathematics. It seeks to highlight some of the discursive strategies employed by the writer / author in composing the plot (intrigue) of their stories. The methodology of the research sought in the Narrative Hermeneutics of its analytical and interpretative basis, being the composition of the plot / intrigue the thread of the task undertaken. The historical narratives elaborated by D'Ambrosio, in the text plane, make a referential cross between the factual representation of the facts and the fictionalization of History.

Keywords: Poetics, rhetoric, world of text, stories of history.

\section{Introdução}

Este artigo apresenta um recorte de uma pesquisa maior, realizada em nível de doutoramento (Marchon, 2018), na qual investigamos a produção textual do educador matemático Ubiratan D’Ambrosio. Observamos especialmente os modos como uma História

Submetido em: 16/03/2019 - Aceito em: 20/12/2019 - Publicado em: 25/12/2019

1 Doutor em Educação pela Universidade Federal Fluminense. Professor da Faculdade de Educação da Universidade Federal Fluminense, Brasil. Email: fabiolennon@id.uff.br

${ }^{2}$ Doutora em Educação pela Universidade de São Paulo. Professora da Faculdade de Educação da Universidade Federal Fluminense, Brasil. Email: mcfantinato@gmail.com 
da Etnomatemática foi escrita em seu mundo próprio a partir de um dos seus principais teóricos.

Um dos objetivos centrais deste trabalho é explorar alguns dos aspectos literários/poéticos e retóricos da produção textual de Ubiratan D'Ambrosio e, em particular, destacar os modos como D’Ambrosio conta histórias da História da Etnomatemática.

Algumas questões que nos auxiliaram nesta empreitada são: (a) Como D’Ambrosio diz algo sobre alguma coisa para alguém em seu mundo do texto? (b) Quais as estratégias discursivas empregadas por D’Ambrosio para compor suas histórias em seus textos?

Defendemos que existem histórias (story) acerca da História (history) da Etnomatemática. Estas, por sua vez, nos informam que a Etnomatemática é uma tendência (teórica, pedagógica, de estudos e de pesquisas) que emerge dentro do contexto da Educação Matemática na década de 1970 (Conrado, 2005; D’Ambrosio, 1990, 1993, 2011b; Rosa \& Orey, 2005, 2014; Valente, 2007). Muitas destas histórias apontam para um personagem: o matemático Ubiratan D'Ambrosio. Ele é considerado o principal idealizador do Programa Etnomatemática, um dos maiores representantes desta área no Brasil e no mundo, e também a principal voz destas histórias (Knijnik, 2004, 2012; Gerdes 1994; Valente 2007; D’Ambrosio 1990, 2011b; Breda e Lima, 2011; Asher e Asher, 1997; Fiorentini \& Lorenzato, 2007; Passos, 2017; Scott, 2011).

Observamos que há uma narrativa histórica da Etnomatemática enunciada por ela mesma, ou melhor, textualizada na produção escrita de alguns pesquisadores deste Programa de estudos e pesquisas (D’Ambrosio, 1990, 1993, 1985a, 1985b, 1986, 2011a, 2011b; Rosa \& Orey, 2014, 2016; Conrado, 2005, Passos, 2017; Knijnik, 2004), assim como também por pesquisadores afiliados à pesquisa histórica em Educação Matemática (Valente, 2007; Muniz, 2013). Um dos elementos comuns a todas estas histórias da História da Etnomatemática é a perspectiva do narrador privilegiado, testemunha ocular dos acontecimentos e personagem principal de muitas das narrativas textualizadas - Ubiratan D'Ambrosio - que, ao narrar sua compreensão dos fatos e interpretar os acontecimentos pretéritos diz aos seus leitores o que houve e como tudo ocorreu.

Não obstante, lê-se na obra assinada por D’Ambrosio, por ele produzida e divulgada, que seu trabalho de cunho teórico possui uma inclinação histórica ${ }^{3}$. De acordo com o seu testemunho (D’Ambrosio, 1990), a escrita do seu trabalho explora holisticamente a História e, em particular, a História da Matemática. E, se D’Ambrosio assume para si uma identificação com a pesquisa histórica, como menosprezar os modos como ele conta histórias da História em seu mundo do texto?

\footnotetext{
${ }^{3}$ A perspectiva histórica assumida na escrita dos textos etnomatemáticos d'ambrosianos é algo que merece alguma atenção. Como se pode perceber em Nobre (2007), o papel de Ubiratan na constituição de uma comunidade de pesquisadores em História da Matemática no Brasil foi fundamental. O educador matemático ocupou posições que, nesse contexto, devem ser mencionadas. Ele foi presidente da Sociedade Latinoamericana de História das Ciências e da Tecnologia entre 1988 e 1992, presidente da Sociedade Brasileira de História da Ciência de 1991 a 1993 e, por fim, presidente da Sociedade Brasileira de História da Matemática (SBHMat) entre 1999 e 2007.
}

Zetetiké, Campinas, SP, v.27, 2019, p.1-14 - e019026

ISSN 2176-1744 
Não questionamos aqui a intenção de verdade associada à ação historiográfica de D'Ambrosio em seus escritos e discursos ou, ainda, a verdade da História por ele enunciada, mas sim, o como da escrita destas histórias. Estamos mais inclinados para uma análise da poética do saber ou, como diria Rancière (2014), interessados no "estudo do conjunto dos procedimentos literários pelos quais um discurso se subtrai da literatura" (Rancière, 2014, p.12); lançamos um olhar mais apurado para as regras "segundo as quais um saber se escreve e se lê" (idem). Importa, portanto, compreender os modos como o discurso de verdade desta História se efetua no plano textual, suas estratégias de convencimento e persuasão (aspecto retórico), a intertextualidade (aspecto literário) e o modo como os acontecimentos são enunciados, contados e narrados (aspecto poético).

A relevância deste trabalho reside no fato de a produção textual de D’Ambrosio ser uma das principais referências teóricas no interior da Etnomatemática no Brasil (Fantinato \& Freitas, 2018; Valente, 2007; Passos, 2017) e, também, por ser D’Ambrosio a principal voz dessa narrativa histórica da Etnomatemática na (e para) a Educação Matemática (Valente, 2007; Muniz, 2013; Rosa \& Orey, 2014, 2016; Conrado, 2005; Breda \& Lima, 2011; D'Ambrosio \& D'Ambrosio, 2007) e, também, por assumirmos que o seu estilo de escrita pode ter influenciado (direta ou indiretamente) parte dos modos como outros pesquisadores desta área no Brasil têm materializado sua própria produção textual. Investigar a produção textual do matemático brasileiro torna-se, neste caso, um dos caminhos para se compreender parte desta História da Etnomatemática enunciada/contada e, em particular, tentar compreender como ela tem sido escrita em seu mundo próprio.

\section{Aspectos teóricos e metodológicos}

Priorizamos neste trabalho documentos textualizados, ou seja, a palavra escrita. A obra produzida e assinada por D'Ambrosio permite investigar seu discurso e suas narrativas e, principalmente, acompanhar o percurso de constituição teórica da Etnomatemática idealizada e defendida por D'Ambrosio no decorrer do tempo. As fontes ${ }^{4}$ pesquisadas foram as mais diversas (Vianna, 2000; Muniz, 2013; Valente, 2007; D'Ambrosio 1979, 1985, 1986, 1990, 1993, 2008, 2003, 2011a, 2011b; Furinguetti, Giacardi, Menguini \& Arzarello, 2008; etc.).

\footnotetext{
${ }^{4}$ A pesquisa desenvolvida na tese de doutorado avançou sobre inúmeras fontes, documentos e textos, não se restringindo aos que são citados neste artigo. Outros documentos foram consultados e, tendo em mente o interesse histórico pelos primeiros anos da Etnomatemática (de Ubiratan D’Ambrosio) e sua emergência nas pesquisas acadêmicas, grande parte dos documentos consultados se encontra no período de 1950 a 1990. Destacam-se alguns: Proceedings of the international Congress on Mathematical Education roceeddings (ICME); Anais dos Encontros Nacionais de Educação Matematica (ENEM); Proceedings of the Interamerican Commitee on Mathematics Education (IACME). Proceedings of the International Congress of Mathematicans (ICM). Consideram-se ainda algumas das fontes documentais que fazem parte da memória das instituições (ICMI; IACME; SBEM) das quais Ubiratan D'Ambrosio fez (ou ainda faz) parte: "The first century of the international commission on mathematical instruction, (1908-2008): reflecting and shaping the world of mathematics education"; "The history of the inter-american commitee on Mathemaics education" "Relatos de memórias: a trajetória histórica de 25 anos da Sociedade Brasileira de Educação Matemática(1988-2013)”. Em relação à produção do autor, recorre-se a um artigo de 2003: "Reminiscências de minha atuação enquanto Presidente do Comitê Interamericano de Educação Matemática/CIAEM".
}

Zetetiké, Campinas, SP, v.27, 2019, p.1-14 - e019026

ISSN 2176-1744 
Os prefácios, posfácios, notas de rodapé, citações e epígrafes (Genett, 2009) dos textos assinados pelo matemático se revelaram importantes para a investigação, pois, nesses espaços, o autor da obra busca dialogar diretamente com o seu leitor revelando-se a partir dos seus enunciados. Escritor, autor e narrador tanto convergem quanto divergem no interior do texto; o trabalho analítico (Marchon, 2018) buscou pontuar estes distanciamentos ou sobreposições.

Observamos no nível do texto os aspectos poético/literário e retórico da escrita da História (Ricoeur, 2012 a, b, c; White 2014; Veyne, 1982). Observa-se, neste sentido, que

[...] o texto é uma entidade complexa de discurso cujos caracteres não se reduzem aos da unidade de discurso ou frase. Por texto não entendo somente nem principalmente a escritura, embora a escritura ponha por si mesma problemas originais que interessam diretamente ao discurso como obra. Com a obra, como a palavra o indica, novas categorias entram no campo do discurso, essencialmente categorias práticas, categorias da produção e do trabalho. Antes de tudo, o discurso é a sede de um trabalho de composição, ou de "disposição" — para retomar palavra da antiga retórica —, que faz de um poema ou de um romance uma totalidade irredutível a uma simples soma de frases (Ricoeur, 2015, p. 336).

Metodologicamente, a pesquisa se inspira na hermenêutica narratológica de Ricoeur (2102a, 2012b, 2012c) e em sua análise acerca da historiografia (Ricoeur, 2012c, 2007), levando-se em conta o aspecto retórico e metafórico (Ricoeur, 2015) da escrita das histórias.

Para o filósofo francês Paul Ricoeur (1913-2005), a noção de texto relaciona-se com o conceito de discurso, mais especificamente, a inscrição do discurso (Ricoeur, 2015, 2012a, 2007). Consequentemente, o texto é marcado pelo aspecto retórico da argumentação, em particular no que diz respeito aos tropos (metáfora, metonímia, sinédoque, ironia) (Ricoeur, 2015) e, em especial, no caso dos discursos metafóricos, que, distanciando-se da oralidade, materializam-se e objetivam-se na forma escrita. As implicações para a produção da escrita da História foram estudadas por Ricoeur (2007, 2012a, 2102b, 2012c) a partir de diferentes pesquisadores. Destaca-se, por exemplo, um fragmento do texto de Ricoeur (2012c) no qual ele apresenta e comenta o pensamento de Hyden White (1928-2018):

A fim de figurar "o que realmente aconteceu" no passado, o historiador tem inicialmente de prefigurar o conjunto dos acontecimentos relatados nos documentos (ibid.). A função poética é desenhar no "campo histórico" itinerários possíveis e dar assim um primeiro contorno a objetos possíveis de conhecimento. O visado é certamente aquilo que realmente aconteceu no passado; o paradoxo é que só se pode designar esse anterior a toda a narrativa prefigurando-o (Ricoeur, 2012c, p. 258).

A prefiguração da qual White fala, e que Ricoeur (2012c) reproduz e explica, se associa à "operação linguística que se desenrola no nível da massa documentária ainda indiscriminada" (idem.). Essa operação, por seu turno, está pautada numa fase de leitura e interpretação dos documentos que antecede a análise e busca essencialmente identificar os discursos que dominam a constituição de um mundo da experiência viva, isto é, histórica. $\mathrm{O}$ trabalho subsequente do historiador é o da composição da intriga, operação eminentemente poética, ou seja, literária, em que a ficção funciona como dispositivo quase-lógico na redescrição do campo histórico. 
As narrativas que emergem dos rastros das memórias, apesar de históricas com intenções de verdade, são ainda, histórias. Para o teórico francês "toda configuração narrativa culmina em uma refiguração da experiência temporal” (Ricoeur, 2012c, p. 3). E, nesse contexto, as histórias da História podem ser entendidas, grosso modo, como ficções verbais (Ricoeur, 2012a) em um mundo possível (o mundo do texto). Segundo Ricoeur,

O que se deve interpretar num texto é uma proposta de mundo que eu possa habitar e nele projetar uma dos minhas mais intrínsecas próprias possibilidades. É aquilo a que eu chamo o mundo do texto, o mundo próprio a este texto único. O mundo do texto não é, portanto o mundo da linguagem cotidiana. Nesse sentido, constitui um novo tipo de distanciamento que pode ser chamado um distanciamento do real de si mesmo. Esse distanciamento que a ficção introduz em nossa apreensão da realidade (Ricoeur, 2007, p.86) (tradução nossa).

Como nos diz o autor, "a realidade quotidiana se metamorfoseia em favor daquilo que poderíamos chamar de variações imaginativas que a literatura opera sobre o real" (Ricoeur, 1978, p.57). Logo, se um texto é qualquer discurso fixado pela escrita (Ricoeur, 2007), nesse caso, a hermenêutica é "a arte de discernir o discurso na obra" (Ricoeur, 1978, p.52).

O fio condutor da analítica-interpretativa é a composição do enredo (intriga) das histórias enunciadas, contadas, narradas - "a composição da intriga constitui um autêntico componente da operação historiográfica" (Ricoeur, 2007, p.250) - , pois, a saber, segundo esse filósofo, "a intriga é a forma literária dessa coordenação: ela consiste em conduzir uma ação complexa de uma situação inicial para uma situação terminal por meio de transformações regradas" (Ricoeur, 2007, p.255).

As categorias que emergem do texto são, dentre outras, a do narrador e da voz da narrativa, as personagens, os conflitos/tensões e os espaços. As personagens, por seu turno, agem (ou deixam de agir) em função dos acontecimentos. Os acontecimentos, em contrapartida, dependem das personagens; há um entrelaçamento. As personagens são "compostas em intrigas" (Ricoeur, 2007, p. 256). E, de acordo com o filósofo francês, "a noção de personagem constitui um operador narrativo da mesma amplitude que a do acontecimento; as personagens são os agentes e os pacientes da ação narrada" (idem).

A História (History) apresenta suas histórias (stories) na tessitura das tramas e, como indicado por Ricoeur (2012 a, b, c), entrecruzando História e ficção a partir das mãos do artesão do texto: o escritor. Para este filósofo, o espaço-tempo da história é quase-ficcional e quase-histórico; trata-se de um entrecruzamento da História e da Ficção ${ }^{5}$ (Ricoeur, 2012c). É necessário destacar que, no caso deste trabalho, D’Ambrosio é o artesão do texto e também uma das personagens de suas próprias histórias.

$\mathrm{Na}$ perspectiva da literalidade da composição do texto de D'Ambrosio observa-se a intertextualidade - e "minha interpretação e análise das fontes que sustentam,

\footnotetext{
5 De acordo com o filosofo francês, "Por entrecruzamento entre história e ficção, entendemos a estrutura fundamental, tanto ontológica como epistemológica, em virtude da qual a história e a ficção só concretizam suas respectivas intencionalidades tomando de empréstimo a intencionalidade da outra" (Ricoeur, 2012c, p. 311). 
academicamente, um cenário histórico, é sempre acompanhada de um colóquio com os ficcionistas que abordam o mesmo cenário" (D’Ambrosio, 2008, p. 20).

No nível do texto, no mundo do texto, fala-se do personagem D'Ambrosio (distinto do homem de carne e osso, sujeito sociohistórico e empírico) e do narrador da história (que, em alguns casos, distancia-se do personagem e do autor/escritor do texto). Considera-se que o escritor, ao narrar suas histórias, projeta-se sobre o texto e cria uma personagem de si mesma e, com isso, faz emergir uma identidade narrativa (Ricoeur, 2007) que habita o espaço discursivo textual.

\section{A investigação}

Grande parte da produção escrita de D'Ambrosio que analisamos/interpretamos esteve inicialmente voltada para a oralidade. É coerente afirmar que, em geral, há um auditório implícito. Podemos assumir que um leitor genérico do texto d'ambrosiano assume a posição de uma audiência em uma plateia virtual.

Muitos dos textos escritos pelo matemático foram produzidos inicialmente para palestras, seminários e plenárias (D’Ambrosio 1979, 1985, 1986, 1990; etc.) e apenas posteriormente incorporados aos seus artigos e livros. $\mathrm{O}$ seu discurso oral e suas narrativas foram materializadas em entrevistas e servem de fonte de informação para diferentes pesquisadores (Vianna, 2000; Valente, 2007; Muniz, 2014; Miarka, 2011; Conrado, 2005).

Como grande parte da História da constituição da Etnomatemática na Educação Matemática acompanha a trajetória profissional do seu criador e divulgador, o D'Ambrosio da Etnomatemática (D'Ambrosio \& D'Ambrosio, 2007; Valente, 2007; D'Ambrosio, 2003; Conrado, 2005; etc.), então, para se compreender esta História da emergência da Etnomatemática, torna-se relevante adentrar as histórias que compõem o mundo do texto d'ambrosiano que narram esta trajetória. Em especial, seguindo-se as indicações metodológicas, acompanhar os encontros com outros personagens na trama narrada.

Tome-se como exemplo o ano de 1963, marco histórico inscrito no trabalho de Conrado (2005) e compartilhado por outros pesquisadores (Rosa \& Orey, 2014), que atesta que a emergência da Etnomatemática de D'Ambrosio está atrelado ao estágio que realizou na NASA (EUA). Revisitamos esta história a partir da narrativa do matemático brasileiro:

Em 63 eu acabei. Eu trabalhava em Cálculo de Variações, e a NASA, junto com o American Mathematical Association, fez um Summer Institute, curso de verão, de oito semanas, quase dois meses em Cornel, e tinha algumas vagas para estrangeiros. Eu escrevi para eles e ganhei uma bolsa, dessa vez bolsa completa: passagem, estadia, tudo. E fui para lá, e passei lá. Aí eu vi um Cálculo de Variações aplicado ao problema de controle de órbita. O problema maior que existia era das naves espaciais se juntarem; já estavam pensando na estação espacial, em problemas de órbitas, problemas de mecânica avançada. Muito, muito bom o seminário. Ali eu conheci o Bellman e outros matemáticos, enfim, na minha área, mas em outra... teoria de controle, sobretudo, tive uma iniciação em teoria de controle, mas nunca me interessei muito. Nessa mesma ida para os Estados Unidos, já aproveitei e passei uns dias em Providence junto com o Fleming. Lá eles viram o que eu estava fazendo, aquelas 
coisas do De Giorgi que eles respeitavam muito, e falaram: você não tem ainda doutorado, é melhor acabar lá. Você não quer vir para pós-doutorado?... Ofereceram um Research Associate, para ir lá e trabalhar com um grupo de pesquisa deles, eu aceitei e ficou combinado. Eles me fizeram um convite formal, por isso eu, a Maria José, a família, as duas crianças ganhamos um green card. A idéia era ir só por um ano. Era um contrato de Research Associate por um ano para dar aula na Brown University. Eu voltei em agosto e defendi minha tese em dezembro e em janeiro de 64 fui para os Estados Unidos; mais uma vez tive um ambiente muito bom. Depois teve o golpe militar e eu não tive coragem de voltar (D’Ambrosio apud Vianna, 2000, p. 105-106).

Note-se que D'Ambrosio é o personagem central e também o narrador dessa história. Não é, contudo, a experiência na NASA que assume relevância em sua narrativa e sim um encontro fortuito com outro personagem. $\mathrm{O}$ "nunca me interessei muito" (idem) enunciado sugere que a experiência com a Teoria do Controle no curso de verão da NASA não merece o título de acontecimento relevante para a História de D'Ambrosio rumo à Etnomatemática. Ocorre uma reviravolta em sua trajetória quando o narrador insere na trama/enredo o personagem Fleming. Sua história, a partir deste encontro, segue outro caminho. Assim, o acontecimento NASA não parece ser tão significativo para a emergência da Etnomatemática de D'Ambrosio como, em geral, se atesta (Conrado, 2005; Rosa \& Orey, 2014; Valente, $2007)^{6}$.

Note-se, no plano do enredo, que, mesmo que o narrador não explicite quem são "eles" - aqueles que o convidam - certamente Fleming está entre esses personagens. A relevância que o narrador dá a Fleming sugere que ele está por de trás do convite; é algo implícito no texto. Note-se, ainda, a encenação dramática (no sentido teatral da expressão) em que se faz uma reconstituição de um diálogo no interior da narrativa, provavelmente fictício e distinto do que de fato foi dito, cria uma atmosfera de verossimilhança no contexto da cena narrada. História e ficção se entrecruzam nesta história.

Em 6 de março de 1969 o Correio da Manhã publicou os nomes de 187 pesquisadores que atuavam na América do Norte e que desejavam voltar para o Brasil. Segundo a reportagem, eles "manifestaram ao adido científico da embaixada brasileira em Washington [...] interesse de regressar imediatamente ao Brasil" (Correio do Amanhã, p.4). Entre os nomes está o do Educador Matemático Ubiratan D’Ambrosio.

É coerente afirmar neste ponto que se o matemático tivesse retornado ao Brasil em 1969, então, muito provavelmente, ele não estaria na universidade que recebeu o convite para participar do projeto da UNESCO na África. Esta informação assume relevância por se tratar de uma parte essencial da narrativa histórica de D'Ambrosio. Ele atesta que foi seu contato

\footnotetext{
${ }^{6}$ Apenas como exemplo, cita-se Conrado (2005): "Podemos, então, considerar como primeiro marco nessa trajetória, o ano de 1963, quando D'Ambrosio é convidado a participar do Summer Institute on Space Mathematics com uma bolsa da American Mathematics Society - AMS. O que seria uma experiência temporária em território americano, acaba por fixa-lo por muitos anos nos Estados Unidos. Diante da instalação de um golpe militar no Brasil, Ubiratan decide aceitar um convite para ser pesquisador associado do Departamento de Matemática da Brown University' (Conrado, 2005, p. 60).
} 
com a realidade africana que despertou nele o interesse pela Etnomatemática - "Qual é a história de vocês? Qual é a matemática desse povo? Aí a etnomatemática começa a criar corpo e essa minha permanência na África foi muito importante." (D’Ambrosio apud Vianna, 2000, p.110). A África é um dos marcos históricos da narrativa d'ambrosiana acerca da gênese da Etnomatemática. Algo recontado, reescrito e até ilustrado em quadrinhos ${ }^{7}$.

Pode-se assumir, no entanto, que as reais condições de possibilidade da emergência da Etnomatemática de Ubiratan D’Ambrosio encontram nos anos de 1963 e 1964 sua nascente. É o período em que o brasileiro encontra o matemático Fleming, defende sua tese de doutorado no Brasil, recebe o convite para trabalhar nos EUA e, finalmente, muda-se para aquele país.

Pode-se dizer que o acontecimento que objetivamente, no plano do texto, conduz D’Ambrosio à África é o contato com Fleming. Em Duarte \& Borges (2007) é possível encontrar alguns indícios que reforçam esta tese. Lê-se que Ubiratan foi aos Estados Unidos em 1963 e lá "visitou o professor Wendell H. Fleming [...] Fleming o recebeu muito bem, oferecendo-lhe uma posição denominada "pesquisador associado"” (Borges \& Duarte, 2007, p.47).

Distanciando-se da dimensão sociohistorica da produção da narrativa e adentrando o do uso da linguagem na escrita da História, cabe evidenciar o uso de estratégias discursivas próprias da retórica. Percorrendo a obra textual de D'Ambrosio tais elementos podem ser objetivamente identificados. Tome-se como exemplo D'Ambrosio (1990): “A responsabilidade dos educadores de matemática com relação ao futuro é central e precisamos entender nosso papel nessa rede complexa de responsabilidades divididas" (D'Ambrosio, 1990, p. 25). São os marcadores linguísticos que acompanham a inscrição do discurso que nos exibem os traços da retórica do discurso. Atesta-se no exemplo uma responsabilidade para os educadores e, esta, é central para o futuro; é preciso, de acordo com o narrador da história, entender "nosso" papel em uma complexa rede de "reponsabilidades divididas". O leitor é enlaçado pelo escritor com a pluralização que o inclui no cenário pintado na história que se conta.

Além disso, em diferentes partes da obra textual produzida por D'Ambrosio, observam-se deslocamentos de sentidos de certas palavras: "sou levado a acreditar que minha proposta educacional representa esperança de redenção para alguns e ameaça para outros" (D’Ambrosio, 1986, p.8). D’Ambrosio, ao contar sua história, recorre a certas palavras (“acreditar", "esperança", "redenção", "missão", etc.) que, deslocadas do seu sentido estrito, usual, exigem do leitor uma compreensão interpretativa do texto. Estabelece-se um vínculo simbólico, no nível do discurso, entre a Etnomatemática e a religião.

\footnotetext{
${ }^{7}$ A narrativa histórica da emergência da Etnomatemática a partir da voz de Ubiratan D’Ambrosio, e que tem sido captada por outros pesquisadores da área, faz parte de uma história em quadrinhos. Esta, por sua vez, resume a História da criação do "Programa de Pesquisa Etnomatemática". O roteiro da história foi produzido com o aval do Grupo de Amigos do Ubiratan (GAU) e se encontra disponível em: https://www.facebook.com/grupodeamigosdoubi/photos/a.736089533150250.1073741827.736084856484051/9 18125501613318/?type=3\&theater(visualizado em 22/11/2016).

Zetetiké, Campinas, SP, v.27, 2019, p.1-14 - e019026

ISSN 2176-1744
} 
O escritor apresenta verdades históricas inquestionáveis em seu texto: "A história nos ensina que a crítica e a censura têm sempre estado presentes na REALIDADE na qual se desenvolve a AÇÃO inovadora" (D’Ambrosio, 1986, p.8. destaque no original); não há espaço para questionamento ou dúvida. Há um ensinamento histórico enunciado que, no contexto da história narrada, apresenta a Etnomatemática como uma ação inovadora. Note-se que é ela, a ação, quem recebe críticas e censura e não propriamente o personagem D'Ambrosio. Uma história de conflito e luta emerge na trama d'ambrosiana enunciada na produção textual da Etnomatemática.

A poética do texto apresenta para o leitor um quadro apocalíptico em que se encena uma história crítica, perturbadora e angustiante e, nela, todos os homens encontram-se à beira da extinção. Sua crítica disfarça-se e assume a forma de questionamento:

Estaremos atingindo o final de um modelo cognitivo em que ao mesmo tempo em que nos permite nos aproximarmos de uma verdade totalizadora, que nos desvenda o pequeno e o grande, o interior e o exterior, nos força a dar o passo final em direção ao sacrifício total, e assim atingirmos a meta existencial, estendendo para toda a espécie a meta da extinção em direção à qual inexoravelmente caminhamos como indivíduos? (D’Ambrosio, 1990, p. 44)

É necessário criar algo novo, diferente, potencialmente revolucionário, que mude os rumos desta história. A Etnomatemática surge, nesse caso, como uma solução poética para a crise instituída na história. É o período de crise enunciado no texto que permite ao autor, posteriormente, apresentar sua proposta educacional. Sua interpretação da realidade e, consequentemente, suas críticas, se organizam a partir desse ponto crítico da história. $\mathrm{O}$ modelo apocalíptico na literatura depende de uma concordância entre a lembrança de uma crise do passado e uma idealização do futuro (Kermode, 2000) que, na história, soluciona a crise enunciada. A constante da história somos nós, seres humanos, ou melhor, os personagens da história que estão sempre no meio, entre o início e um fim provável. Nesse contexto, a proposta da Etnomatemática é "conduzir a humanidade, como um todo, a dias melhores" (D’Ambrosio, 1990, p. 78). Age-se no presente a partir das previsões que se faz para o futuro tendo como base as crises do passado.

O escritor do texto etnomatemático usa recorrentemente o advérbio "naturalmente". Fala-se de algo (supostamente) óbvio e, poder-se-ia dizer, evidente para todos e, por isso mesmo, indiscutível ${ }^{8}$. Cria-se uma verdade histórica ao se afirmar/enunciar uma verdade naturalizada: "Naturalmente, essa tentativa de classificar estilos de abordagem da realidade, da natureza, é grega e assim matemática; como a concebemos nos nossos sistemas escolares, resulta do pensamento grego." (D’Ambrosio, 1990, p. 6). A história escrita está fortemente apoiada na retórica do discurso.

\footnotetext{
${ }^{8}$ A ficcionalização da História apoia-se na estratégia de persuasão e convencimento do qual o uso do advérbio "naturalmente" é apenas um dos componentes. Ex.: (a) "Naturalmente, não são os trabalhos de ontem que interessam aos egressos da escola do amanhã" (D’Ambrosio, 1990, p. 16); (b) "Naturalmente, manejar quantidades e consequentemente números, formas e relações geométricas, medidas, classificações, em resumo tudo o que é do domínio da matemática elementar, obedece a direções muito diferentes...” (D’Ambrosio, 1990, p. 17); etc.
}

Zetetiké, Campinas, SP, v.27, 2019, p.1-14 - e019026

ISSN 2176-1744 
Quanto aos personagens, o narrador fala tanto de seres reais (não fictícios) quanto de irreais (literários/fictícios) - "ideology, implicit in dressing, housing, titles, so superbly demounced by Aimée Cesaire in La Tragédie du Roi Christophe" (D’Ambrosio, 1985, p. 77), tem-se neste fragmento um personagem não-fictício (Aimée Cesaire) e um personagem fictício (Rei Christophe) que surgem na composição do enredo para fundamentar as reflexões acerca da ideologia educacional enunciada pelo escritor em sua obra. Entrecruzam-se, novamente, História e ficção para compor a intriga da história narrada.

Dentre as muitas estratégias discursivas na composição do texto de D’Ambrosio, observa-se a intertextualidade. $\mathrm{O}$ escritor convoca para interior do seu mundo do texto as vozes de outros personagens.

Um exemplo de intertextualidade na obra escrita por D'Ambrosio é a voz do Dom Quixote, personagem criado por Cervantes (1547-1616). O narrador recorre às palavras do "grande mestre" (D’Ambrosio, 1986, p.8) e toma de empréstimo a seguinte fala: "Perdoname, amigo, de La ocasion que te He dado de parecer loco como yo, haciéndote caer em El error em que yo He caído, de que hubo y hay caballeros andantes em El mundo" (D'Ambrosio, 1986, p.8); esta citação literária pode ser lida em outros trabalhos de D'Ambrosio ${ }^{10}$.

Defendemos que há uma encruzilhada intertextual nos escritos d'ambrosianos. Proliferam nomes, referências e citações; em muitos casos exige-se do leitor um esforço investigativo ou, simplesmente, sua crença no que é dito. Unem-se, em um mesmo parágrafo Flaubert, Lada, Madame Bovary, Padre Padrone e Paulus Gerdes (D’Ambrosio, 1990, p.26). Todos estes personagens são, direta ou indiretamente, para o escritor do texto, referências acerca da "rede complexa de influências que permeia a educação matemática" (D'Ambrosio, 1990, p.26).

Há ainda, na composição do texto etnomatemático de D'Ambrosio, um elemento dramático a partir do uso de diálogos. A teatralização das histórias narradas são mais recorrentes em suas entrevistas - "O Cecconi precisava de um assistente; conversou: tem algum colega? Ah! tenho o Ubiratan que está dando aula na PUC lá em Campinas e em São Paulo" (Vianna, 2000, p.102) - mas, não raro, emergem em seus trabalhos teóricos.

Em D’Ambrosio (1985), no terceiro capítulo dessa obra, entre as páginas 51 e 56, o escritor se apoia em um fragmento de uma obra literária - As confusões do jovem Törless (publicado em 1906), de Robert Musil (1880-1942) — para exemplificar e reforçar seus argumentos em favor de uma nova postura diante da matemática escolar e, simultaneamente, contra uma tradição do ensino da matemática escolar. Têm-se quatro páginas com diálogos de uma obra ficcional que agem como dispositivos de sensibilização do público (auditório/leitor). Neste contexto emerge a estratégia da teatralização em que diálogos encenam situações quase-reais e se mostram verossímeis para o leitor:

\footnotetext{
9 Tradução nossa: "Ideologia, implícita em vestimentas, moradia, títulos, tão devidamente denunciadas por Aimée Cesaire em La Tragédie du Roi Christophe"

${ }^{10}$ Epígrafe do último capítulo de D’Ambrosio (1985). A fala em destaque faz parte da obra de Cervantes, "the death of Don Quixote". Tradução nossa: "Perdoe-me, meu amigo, por ser a causado de você parecer tão louco quanto eu, levando você a cair no mesmo erro, em acreditar que ainda há cavaleiros errantes no mundo". 
- Escute, você entendeu aquilo há pouco?

- O quê?

- Esse negócio de números imaginários?

- Sim. Não é tão difícil. A gente apenas tem de lembrar que a raiz quadrada de um negativo é a unidade básica com que se trabalha.

- Pois é isso. Esse número nem existe. Qualquer cifra, algarismo, seja negativo ou positivo, tem como resultado algo positivo quando elevado ao quadrado. Por isso não pode existir um algarismo cuja raiz quadrada fosse negativa. (D'Ambrosio, 1985, P.52). (Tradução livre).

As muitas vozes que ecoam no texto etnomatemático d'ambrosiano, em muitos casos, partem da "boca" do narrador, e são inscritos no texto pelas mãos do escritor, e, não raro, deixam as marcas do personagem etnomatemático transparecer. Não é necessariamente o sujeito de carne e osso, o escritor, quem fala; é o seu personagem, o D'Ambrosio da história, usando as máscaras do narrador e se apropriando das vozes de outros personagens.

\section{Considerações finais}

A investigação maior revelou algumas das características da escrita da História na obra textual assinada por D'Ambrosio. Este artigo apresenta alguns destes aspectos.

Primeiramente cabe evidenciar que grande parte da produção textual de D'Ambrosio analisada foi inicialmente pensada para a oralidade (palestras, seminários, conferências, etc.) e, por isso mesmo, nota-se o caráter retórico do discurso. A análise evidenciou que, implicitamente, o intuito do texto é convencer e persuadir o leitor, enlaçando-o em uma trama de lutas e conflitos.

Destacam-se também a intertextualidade e a pluralidade de personagens na escrita do texto etnomatemático de D'Ambrosio. O escritor recorre às vozes de outros personagens, sejam eles fictícios ou não, para fundamentar seus argumentos.

Uma das estratégias literárias utilizadas para compor a intriga de uma de suas obras (D’Ambrosio, 1990) é a do fim apocalíptico anunciado (e enunciado) que exige uma mudança de direção (da concepção de homem, do uso da ciência, da educação matemática, etc.).

Em alguns casos, o escritor recorre à dramatização, apresenta diálogos, e teatraliza a história narrada.

D'Ambrosio, ao contar histórias da História, entrelaça ficção e realidade que, nos termos de Ricoeur (2012c) se trata de um entrecruzamento referencial da História e da Ficção.

Por fim, esperamos que este trabalho possa contribuir para o debate crítico acerca da produção textual da Etnomatemática, em particular no que diz respeito à escrita das muitas histórias da História que emergem em seu interior, e, principalmente, possibilitar novos olhares e interpretações para obra de D'Ambrosio.

\section{Agradecimentos}


DOI: $10.20396 /$ zet.v27i0.8655367

Agradecemos ao GETUFF, Grupo de Etnomatemática da UFF, pela troca de ideias.

\section{Referências}

Ascher, M., Ascher, R. (1997). Ethnomathematics. In A. B. Powell, A. B. \& M. Frankenstein (Eds.), Ethnomathematics: Challenging eurocentrism in mathematics education. (pp.25 50). New York, NY: State University of New York Press.

Anais do Primeiro Encontro Nacional de Educação Matematica (I ENEM). Disponível em: <http://www.sbembrasil.org.br/files/enemI.pdf (visualizado em 5/7/2017)>.

Breda, A., Lima, V. M. R. (2011). Etnomatemática sob dois pontos de vista: a visão "D’Ambrosiana" e a visão Pós-Estruturalista. Revista Latinoamericana de Etnomatemática. 4(2), 4- 31.

Conrado, A. L. (2005). A pesquisa brasileira em etnomatemática: desenvolvimento, perspectivas, desafios. Dissertação (Mestrado em Educação) Programa de Pós-graduação em Educação, Universidade de São Paulo. São Paulo: USP.

Correio

da

Manhã.

Disponível

em:

<http://memoria.bn.br/DocReader/Hotpage/HotpageBN.aspx?bib=089842_07\&pagfis=1

00117\&url=http://memoria.bn.br/docreader\#>. Acervo digital. Acesso em 4/3/2017.

D'Ambrosio, U. (1979). Overall goals and objectives of mathematics education. New trends in mathemathics teaching. ICMI/UNESCO. v. IV, 180-198.

D'Ambrosio, U. (1985a). Socio-Cultural bases for Mathematics education. Transcrição de uma palestra realizada pelo autor. São Paulo: UNICAMP.

D'Ambrosio, U. (1985b). Ethnomathematics and its Place in the History and Pedagogy of Mathematics. For the Learning of Mathematics. Canada: FLM Publishing Association. 5(1), 44-48.

D’Ambrosio, U. (1986). Da realidade à ação: reflexões sobre Educação e Matemática. São Paulo: Summus; Campinas: Ed. Da Universidade Estadual de Campinas.

D’Ambrosio, U. (1990). Etnomatemática: Arte ou técnica de explicar ou conhecer. São Paulo: Ática.

D’Ambrosio, U. (1993). Etnomatemática: Um Programa. Educação Matemática em Revista. Blumenau, SC: SBEM. 1(1), 5-11.

D'Ambrosio, U. (2003). Reminiscências pessoais de minha atuação enquanto Presidente do Comitê Interamericano de Educação Matemática/CIAEM. Sessão plenária na XI Conferência InterAmericana de Educação Matemática. Blumenau, 13 a 17 de jul.

D’Ambrosio, U. (2008) Entrevista Luis H. Pellanda. Revista Rascunho, ano 9, numero 102, p. 20.

D’Ambrosio, U. (2011a). Etnomatemática: elo entre as tradições e a modernidade. Coleção tendências em Educação Matemática, 4. Belo Horizonte: Autêntica.

D’Ambrosio, U. (2011b). Uma História concisa da Matemática no Brasil. Petrópolis: Vozes. 
Fiorentini, D., Lorenzato, S. (2007). Investigação em educação matemática: percursos teóricos e metodológicos. Coleção formação de professores. Campinas: Autores Associados.

Genett, G. (2009). Paratextos editoriais. São Paulo: Ateliê.

Gerdes, P. (1994) Reflections on Ethnomathematics. In For the Learning of Mathematics.14(12), 19-22.

Kermode, F. (2000). The sense of an ending: studies in the theory of fiction. New York: Oxford University Press.

Knijnik, G. (2004). Itinerários da etnomatemática: questões e desafios sobre o cultural, o social e o político na educação matemática. In G. Knijnik, F. Wanderer, \& C. J. Oliveira. (Orgs.). Etnomatemática, currículo e formação de professores. (pp.19-38). Santa Cruz do Sul: EDUNISC.

Menguini, M., Furinguetti, F., Giacardi, L. \& Arzarello, F. (Eds).(2008). The first century of the international commission on mathematical instruction, (1908-2008): reflecting and shaping the world of mathematics education. Roma: Instituto Della Enciclopedia Italiaba Fondata da Giovanni Treccani.

Miarka, R. (2011). Etnomatemática: do ôntico ao ontológico. Tese (doutorado). Universidade Estadual Paulista Júlio de Mesquita Filho.Rio Claro: UNESP.

Muniz, N. C. (2013). Relatos de memórias: a trajetória histórica de 25 anos da Sociedade Brasileira de Educação Matemática (1988-2013)]. São Paulo: Editora Livraria da Física.

Nobre, S. R. (2007). Ubiratan D'Ambrosio e o movimento científico e institucional da história da matemática no Brasil. In W. R. Valente. (org). Ubiratan D'Ambrosio: conversas; memórias; vida acadêmica;orientandos;educação matemática; etnomatemática; história da matemática; inventário sumário do arquivo pessoal. (pp.131142). São Paulo: Annablume; Brasília: CNPQ.

Passos, C. M. (2017). Condições de Produção e Legitimação da Etnomatemática. Tese (doutorado). Programa de Pós-Graduação em Educação da Universidade Federal de São Carlos: São Carlos, SP.

Pellanda, L. H. (2008). Manifestações criativas. Revista Rascunho, ano 9, n. 102, p.20. Disponível em: <http://rascunho.com.br/wpcontent/uploads/2012/05/Book_Rascunho_102.pdf>. Acesso em 06/08/2016.

Ricoeur, P.(1978). O Conflito das interpretações: ensaios de hermenêutica. Tradução Hilton Japiassu. Rio de Janeiro: Imago Editora LTDA.

Ricoeur, P. (1990) Interpretação e ideologias. Tradução Hilton Japiassu. Rio de Janeiro: Francisco Alves.

Ricoeur, P. (2007). A Memória, a história, o esquecimento. Tradução Alain François [et al.]. Campinas, SP: Editora da Unicamp.

Ricoeur, P. (2011). Teoria da interpretação: o discurso e o excesso de significação. Lisboa: Edições 70.

Ricoeur, P. (2012a). Tempo e narrativa 1: A intriga e a narrativa histórica. São Paulo: Martins Fontes. 
Ricoeur, P. (2012b). Tempo e narrativa 2: A configuração do tempo na narrativa de ficção. São Paulo: Martins Fontes.

Ricoeur, P. (2012c). Tempo e narrativa 3: O tempo narrado. São Paulo: Martins Fontes.

Ricoeur, P. (2015). A Metáfora Viva. Tradução Dion Davi Macedo. Coleção Leituras Filosóficas. São Paulo: Edições Loyola.

Rosa, M., Orey, D. C. (2005). Raízes históricas do programa etnomatemática. Educação Matemática em Revista, v. 12, n. 18-19, 5-14.

Rosa, M., Orey, D. C. (2014). Fragmentos Históricos do Programa Etnomatemática. (pp.335-358). In Anais/Acta do $6^{\circ}$. Encontro Luso-Brasileiro de História da Matemática.

Rosa, M., Orey, D. C. (2016). State of the Art in Ethnomathematics. In M.R., U. D’Ambrosio, D. C. Orey, D. C., L. Shirley, W. V. Alangui , P. Palhares \& M. E. Gavarrete Current and future perspectives of ethnomathematics as a program.(pp.1138). ICME13-Topical Surveys. London, England: Springer Open.

Scott, P. (2011). The Intellectual Contributions of Ubiratan D'Ambrosio to Ethnomathematics. (pp.1-6). XIII Interamerican Conference on Mathematics Education (CIAEM-IACME), Recife, Brasil. Disponivel em: http://ciaemredumate.org/ciaem/documentos/historiaCiaem/Scott,\%20mesa\%20\%20plenaria\%202.p df (visualizado em 3/6/2016)

Veyne, P. M. (1982). Como se escreve a história: Foucault revoluciona a história. Brasília: Editora Universidade de Brasília.

Valente, W. R. (Org.). (2017). Ubiratan D'Ambrosio: conversas; memórias; vida acadêmica; orientandos; educação matemática; etnomatemática; história da matemática; inventário sumário do arquivo pessoal. São Paulo: Annablume; Brasília: CNPq.

Vianna, C. R. (2000). Vidas e circunstâncias na Educação Matemática. Tese de doutorado. Faculdade de Educação da Universidade de São Paulo. São Paulo: USP.

White, H. (2014). Trópicos do Discurso: Ensaios sobre a crítica da cultura. São Paulo: Editora da Universidade de São Paulo. 